\title{
Biological roles of CCAAT/Enhancer-binding protein delta during inflammation
}

\author{
Chiung-Yuan Ko ${ }^{1,2}$, Wen-Chang Chang $^{3}$ and Ju-Ming Wang ${ }^{3,4,5,6^{*}}$
}

\begin{abstract}
CCAAT/enhancer-binding protein delta (CEBPD) belongs to the CCAAT/enhancer-binding protein family, and these proteins function as transcription factors in many biological processes, including cell differentiation, motility, growth arrest, proliferation, cell death, metabolism and immune responses. The functional diversity of CEBPD depends, in part, on the cell type and cellular context, which indicates that CEBPD could interpret a variety of cues to adjust cellular responses in specific situations. Here, we review the regulation of the CEBPD gene and its function in response to inflammatory stimuli. We also address its effects in inflammation-related diseases through a discussion of its recently discovered downstream targets. Regarding to the previous discoveries and new insights in inflammation-associated diseases, suggesting CEBPD could also be a central gene in inflammation. Importantly, the results of this study indicate that the investigation of CEBPD could open a new avenue to help better understand the inflammatory response.
\end{abstract}

\section{Introduction}

CCAAT/enhancer-binding protein delta (CEBPD) is an intronless gene that encodes a 269 -amino acid protein belonging to the CCAAT/enhancer-binding protein family of proteins, which are known to function as transcription factors in cellular differentiation [1-3], metabolism [4] and immune responses [5]. At present, six C/EBP members have been identified in humans: CEBPA (C/EBP, RcC/ EBP-1), CEBPB (NF-IL6, LAP, CRP2, NF-M), CEBPG (Ig/EBP-1), CEBPD (NF-IL63, CRP3, CELF, RcC/EBP2), CEBPE (CRP-1) and CEBPZ (CHOP-10, GADD153). All of the members of this family contain very diverse $\mathrm{N}$ termini, a highly conserved ( $>90 \%$ identity) basic leucine zipper domain and a basic domain for dimerization and DNA binding at their $\mathrm{C}$ termini [6]. Moreover, several posttranslational modifications, including acetylation, sumoylation and phosphorylation were also identified on C/EBP family members. Therefore, the highly conserved DNA binding domains explain how C/EBP family members can recognize similar DNA sequences in in vitro and in vivo DNA binding assays [7-10] but show diverse functions in cells, which may result from interaction with

\footnotetext{
* Correspondence: yumingw@mail.ncku.edu.tw

${ }^{3}$ Graduate Institute of Medical Sciences, College of Medicine, Taipei Medical University, Taipei 11031, Taiwan

${ }^{4}$ Institute of Bioinformatics and Biosignal Transduction, College of Bioscience and Biotechnology, National Cheng Kung University, Tainan 70101, Taiwan Full list of author information is available at the end of the article
}

various proteins involving in transcriptional regulation or post-translational modifications.

\section{Review}

Regulation of CEBPD expression during inflammation

The expression level of CEBPD is typically low in most cells at normal physiological conditions but is rapidly induced by external stimuli including glucocorticoids [11-13], insulin $[8,14,15]$ and growth factors, e.g., epidermal growth factor [16]. In inflammatory environments, CEBPD has been suggested to be activated by inflammatory factors, such as interleukin-6 (IL-6) [17,18], lipopolysaccharides (LPS) [19-25], interferon- $\alpha$, interferon- $\gamma$ (IFN- $\gamma$ ) [26], tumor necrosis factor- $\alpha$ (TNF $\alpha$ ) [27-30], prostaglandin E2 (PGE2) [31-33] and interleukin-1 $\beta$ (IL-1 $\beta$ ) $[6,29,30,34,35]$. Although the above studies suggested that CEBPD contributes to proinflammation, a study demonstrated that CEBPD mediates in IFN- $\gamma$ - and IL- $1 \beta$ - induced antiapoptosis and anti-inflammation in pancreatic $\beta$-cells [36]. However, the details including signaling pathways and responsive transcription factors in response to the above stimuli to regulate the activation of $C E B P D$ gene remain less characterized.

In response to inflammatory stimuli, CEBPD gene transcription can be activated through the phosphatidylinositol 3-kinase [37], p38 [16,30], JAK [18], JNK [21] and PKA [31] signaling pathways. Interestingly, in addition to transcriptional activation through the $C E B P D$ promoter, a recent 
study suggested that the abundance of CEBPD can be regulated at both posttranscriptional and posttranslational levels. In macrophages, nuclear HuR, an RNA-binding protein, responds to PGE2 and is shuttled to the cytoplasm to stabilize CEBPD mRNA [32]. In addition, the E3 ubiquitin ligase, seven in absentia homolog 2 (SIAH2), was suggested to be involved in posttranslational regulation through the polyubiquitination of CEBPD and downstream degradation via the proteasome in breast cancer cells [38]. However, it is still unclear whether this SIAH2-mediated degradation of CEBPD commonly occurs in inflamed cells.

\section{Role of CEBPD in cyclooxygenase 2 (COX-2) regulation}

Prostaglandins play important roles in many biological processes, including cell division, immune responses, blood pressure regulation, ovulation, bone development and wound healing [39]. Prostaglandin-endoperoxide synthase 2, also known as COX-2, is an inducible enzyme whose expression is mainly regulated at the transcription level and can be induced by cytokines, growth factors, phorbol esters and endotoxins. In the past decade, tremendous progress has been made in understanding the functional roles of COX-2 in cell growth, cell death, cell motility and tumorigenesis. C/EBP family members have been suggested to be involved in regulating $\mathrm{COX}-2$ transcription through direct binding to the promoter region of the COX-2 gene. CEBPB and CEBPD bind to the COX-2 promoter in chondrocytes following IL-1 $\beta$ treatment [40]. Moreover, mouse CEBPD (Cebpd) is involved in LPS- and proteasome inhibitor-induced $\mathrm{COX}-2$ gene expression in murine RAW 264.7 macrophages and alveolar epithelial cells, respectively [41,42]. Interestingly, prostaglandin E2 (PGE2), a COX-2 enzymatic product, can induce CEBPD gene expression [32] (Wang JM et al., unpublished results). These results suggested that the regulation of COX-2 and CEBPD could be functioning in a positive-feedback loop. On the other hand, the activation of p38 mitogen-activated protein kinase (MAPK) has been observed in response to IL-1 $\beta$ or TNF $\alpha$ treatment [43-45] and has been suggested to be involved in the activation of CEBPD transcription [46,47]. However, whether p38-mediated CEBPD activation commonly participates in $C O X-2$ gene regulation in inflamed cells remains an open question and needs to be further clarified.

In our previous study, we also showed that the posttranslational modification of CEBPD is involved in COX-2 regulation. The sumoylated-LAP1 (CEBPB variant) and CEBPD both act as mediators in modulating HDAC4 recruitment on the COX-2 promoter. Upon EGF treatment, the instantly induced nonsumoylated CEBPD can be a positive regulator that replaces the sumoylated-LAP1 and CEBPD. This replacement will increase the p300 binding and form an intact initiation of the activation complex to stimulate COX-2 transcription [9]. These studies indicated that the post-translational modifications of CEBPD protein also responsible for CEBPD-mediated transcriptional regulation. In addition, the histone deacetylase inhibitor, trichostatin $\mathrm{A}$, has a positive effect on LPS-induced COX-2 transcription. It was suggested to be regulated by increasing the recruitment of CEBPA and CEBPB, but not CEBPD, to the $C O X-2$ promoter because the CEBPD expression was attenuated [48].

\section{The roles of CEBPD during acute inflammation}

Activation of CEBPD has been observed in several acute inflammation diseases. However, the detailed mechanisms and regulations involving CEBPD need to be studied extensively. The acute-phase response (APR) protein takes part in the early and nonspecific (but highly complex) reaction of an organism in response to a variety of injuries, such as bacterial infection, tissue injury, extensive bleeding, LPS, turpentine oil, heavy metals, thermal injury or surgery $[19,49,50]$. The liver has been believed to play an important role in the production of APR during the early stages of acute inflammation. CEBPA, CEBPB and CEBPD were reported to regulate APR expression in liver cells $[17,51]$. Poli et al. demonstrated that the CEBPs involved in the induction of APR genes are linked to newly synthesized, NF- $\mathrm{kB}$ - and STAT3-regulated CEBPB and CEBPD proteins [35]. Moreover, phosphorylated CEBPD mediates serum amyloid A gene expression in APR-induced inflammation in rabbit liver [52].

$\mathrm{NF}-\mathrm{kB}$ has long been considered to be involved in the prototypical proinflammatory response that is largely based on the role of NF- $\mathrm{kB}$ in the induction of proinflammatory cytokines, chemokines and adhesion molecules. CEBPD can crosstalk with NF-kB in inflamed and immune cells. In Toll-like receptor 4 (TLR4)-induced macrophage activation, NF- $\mathrm{kB}$ binds to the $C E B P D$ promoter and activates $C E B P D$ transcription. Then, CEBPD binds to the $I L-6$ promoter and cooperates with NF-kB to fully activate $I L-6$ transcription [53]. CEBPD also can act as an amplifier of NF- $\mathrm{kB}$-mediated transcription, which discriminates transient and persistent TLR4 signals, thus facilitating the sustained expression of the inflammatory response [53]. In addition, a recent study showed that CEBPD activates TLR4 gene expression in macrophages and a CEBPD downstream target, F-box and WD repeat domain containing protein 7 alpha, would feedback negatively and downregulate CEBPD to attenuate TLR4 inflammatory signaling [22]. These discoveries suggest that TLR4 and CEBPD could form a regulatory loop in macrophages.

In addition to the classical NF- $\mathrm{KB}$ and MAPK pathways, LPS was shown to activate I $\mathrm{\kappa B}$ kinase $\varepsilon$, leading to the phosphorylation and activation of CEBPD [23]. However, it has also been reported that low-dose LPS fails to activate the classical NF-kB pathway and contributes to the 
leaky and mild elevation of proinflammatory mediators. Selectively removing the suppressive nuclear receptors, including peroxisome proliferator-activated receptor $\alpha$ and retinoic acid receptor, on the promoter regions of proinflammatory mediators activates CEBPD in an interleukin-1 receptor-associated kinase 1-dependent manner [24]. As a critical mediator of LPS-induced acute lung injury, CEBPD can be repressed by the transcription factor Miz1 through recruiting the histone deacetylase HDAC1, further contributing to the suppression of inflammation [54,55]. Meanwhile, suppressor of cytokine signaling 3, a negative regulator of IL-6 signaling, has a protective role in LPS-induced acute lung injury by suppressing CEBPD activity [56]. CEBPD-dependent macrophage mobilization also plays a key role in contributing to the host's defense against bacterial infection [57] and exaggerates bacterial dissemination through platelet-activating factor receptor-dependent bacterial translocation in pulmonary infection [58]. In addition, Cebpb- or Cebpd-deficient macrophages showed impaired induction of IL- 6 and TNF $\alpha$ stimulated by several TLR ligands $[54,59,60]$. Furthermore, both CEBPB and CEBPD are key transcription factors that regulate the $\mathrm{Fc} \gamma$ receptor-mediated induction of TNF $\alpha$, macrophage inflammatory protein 2 and $1 \alpha$ in macrophages [61]. Induction of disseminated intravascular coagulation in CEBPD-deficient mice decreased endotoxin-induced systemic inflammation when compared with wild-type mice, as evident from the decreased plasma levels of tumor necrosis factor-alpha and IL-6 [62]. On the other hand, CEBPD mediated the activation of the LPSinduced anti-inflammatory factor interleukin 10 in mouse macrophages [21]. Our results showed that CEBPD expression can be induced in both M1 and M2 macrophages (Wang JM et al. unpublished results). These findings implied that CEBPD could interact with different components in response to various inflammatory cytokines and plays opposite roles in initiating and resolving the inflammatory response. Interestingly, miR let-7c, which targets CEBPD, has been clarified in promoting M1 macrophage polarization and diminishing M2 phenotype expression [25]. This study further noted the possibility that CEBPD could play a regulator to switch the M1/M2 population during inflammation. Taken together, the above discoveries and controversial observations imply that CEBPD possesses a dual role in immunity/inflammation reactions and indicates that the dissection and interpretation of CEBPD's function during inflammation is complex.

\section{CEBPD during neuroinflammation and inflammation- related diseases}

Despite the large amount of studies that have been conducted and the solutions that have been proposed for clinical applications in chronic inflammatory diseases, our knowledge base is still not sufficient to effectively treat these diseases. Thus, the identification and investigation of novel or less-characterized, inflammation-related genes are important. The activation of CEBPD has been observed in many autoimmune and age-associated chronic inflammation diseases, such as atherosclerosis [63], type 2 diabetes [64], rheumatoid arthritis (RA) [65], Alzheimer's disease (AD) [66] and Parkinson's disease [67]. Recently, a more detailed involvement of CEBPD in some of these inflammation-related diseases, and even in the tumor microenvironment, has been elucidated.

\section{CEBPD in $A D$}

Though the increased levels of CEBPA and CEBPB at sites of neuroinflammation or neural damage have been mentioned [68], the identification and function of CEBPmediated transcriptional regulation and the target genes remain rarely investigated. An immunohistochemistry assay revealed that the location of CEBPD is consistent with the cytokine-laden milieu of the $\mathrm{AD}$ neocortex and limbic cortex, and CEBPD is qualitatively more abundant and stains intensely in astrocytes of $\mathrm{AD}$ patients [66]. This observation raised several interesting questions, including whether the impairment in memory and cognition as well as the personality change, all of which are characteristics of $\mathrm{AD}$ patients, are due to the increased levels of CEBPD in astrocytes.

Activated phagocytic microglia also interact with astrocytes and neural cells to fight off infections as quickly as possible with minimal damage to healthy brain cells. In $\mathrm{AD}$, phagocytic microglia travel to the site of injury in the inflamed brain to engulf the offending materials. We found that astrocytic CEBPD has the ability to attenuate macrophage-mediated phagocytosis of damaged neurons. One CEBPD target, pentraxin-3 (PTX3, also known as TNFAIP5 or TSG-14), participates in the attenuation of macrophage-mediated phagocytosis of damaged neurons [29]. These results provided the first molecular evidence indicating that astrocytic CEBPD and CEBPD-regulated PTX3 play a role in the accumulation of damaged neurons and repair of brain damage. It was also suggested that the detection of PTX3 in cerebrospinal fluid could be used as a diagnostic tool for AD progression. Moreover, CEBPD also regulates the chemoattractive factor gene monocyte chemotactic protein-1 (MCP-1) and the migrationpromoting genes matrix metalloproteinase (MMP)-1 and MMP-3. Once astrocytic CEBPD is induced by IL-1 $\beta$, the recovered GSK3 $\beta$ activity phosphorylates CEBPD at serine 167 (ser167), which then promotes the migration and activation of microglia/macrophages [30] through MCP-1 and MMP-1, respectively. Meanwhile, the use of the GSK3 $\beta$ inhibitor $\mathrm{LiCl}$ in this study suggested that the effect of $\mathrm{LiCl}$ in the clinic may not only act on neural cells but could also result from the inhibition of CEBPD in 
astrocytes. Furthermore, an increase in apoptotic astrocytes was observed in AppTg/Cebpd $d^{-1-}$ mice [an Alzheimer disease mouse model (APPswe/PS1/E9 bigenic) crossed with Cebpd-deficient mice], thereby suggesting that CEBPD plays a functional role in contributing to the anti-apoptotic ability of astrocytes [69]. The Zinc Finger Protein 179 (ZNF179) gene is activated by CEBPD and mediates CEBPD-induced anti-apoptosis in astrocytes by collaborating with the transcription repressor PLZF to inactivate the expression of the proapoptotic genes insulin-like growth factor-binding protein 3 and BCL2-interacting killer [69]. The biological function of CEBPD and its downstream target genes in astrocytes are indicated in Figure 1.

\section{CEBPD in Traumatic brain injury (TBI)}

TBI is also known to increase the expression of amyloid precursor protein (APP) [70]. Many studies have reported that TBI-induced $A \beta$ accumulation can further contribute to $\mathrm{AD}$ formation [71,72], but the detailed mechanisms of TBI progression and its association with $A D$ formation remain less characterized. CEBPD has been reported to be upregulated in the cortex of TBI rats [73]. As mentioned above, Ko et al. showed that astrocytic CEBPD levels increase in response to $A \beta$ and proinflammatory factors [29]. Therefore, CEBPD could be the link between TBIinduced $\mathrm{A} \beta$ accumulation and $\mathrm{AD}$ pathogenesis. However, this speculation requires further study. In addition, inducible nitric oxide synthase (iNOS) deficiency prevented beta-amyloid deposition, astrocytosis, microgliosis and disease progression in APPTg mice [74]. CEBPD also upregulates neurotoxic iNOS expression in glial cells [75]. In Cebpd $d^{-1-}$ mice, systemic LPS-induced brain expression of iNOS, TNF $\alpha$, IL-1 $\beta$ and IL-6 was attenuated [76]. These results demonstrated that CEBPD plays a crucial role in regulating proinflammatory gene expression in glial activation. However, the detailed mechanisms and the in vivo relevance of the roles of glial CEBPD and iNOS in neuroinflammation diseases, including TBI, remain unclear.

\section{CEBPD in RA}

Coincident with the increased levels of serum $C$-reactive protein and synovial IL-6, increased CEBPB and CEBPD expression was detected in synovial tissue of patients with RA [65]. Macrophages have been suggested to play a central immunoreactive role in RA $[77,78]$ due to their prominent numbers at the cartilage-pannus junction. In RA, CEBPD expression was mainly observed in macrophages [65] and compared with WT mice, reduced pannus formation and greater joint architecture integrity were observed in the paws of collagen-induced arthritis Cebpddeficient mice [79]. Using cytokine array and microarray analyses, we identified several secretory factors, including chemokine (C-C motif) ligand 20 (CCL20), chemokine (C$\mathrm{X}-\mathrm{C}$ motif) ligand 1 (CXCL1), IL-23A and tumor necrosis factor alpha-induced protein 6 (TNFAIP6), that were directly regulated by CEBPD in macrophages [79]. A loss of function assay showed that CCL20, IL23A, CXCL1 and TNFAIP6 contributed to the migration and proliferation of synoviocytes, but only the latter two proteins were involved in the tube formation of endothelial cells [79]. Interestingly, two potent anti-inflammatory molecules, inotilone and rosmanol [80,81], which are putative CEBPD inhibitors, were shown to inhibit the migration and proliferation of rat fibroblast-like synoviocytes as well as the tube formation of HUVECs [79]. Taken together, the elucidation of CEBPD biology and its downstream effectors could be helpful in the diagnosis of RA, and these factors could potentially serve as therapeutic targets for RA therapy.

\section{CEBPD in multiple sclerosis (MS)}

As an autoimmune inflammatory disease, MS is the prototypical inflammatory demyelinating disease of the

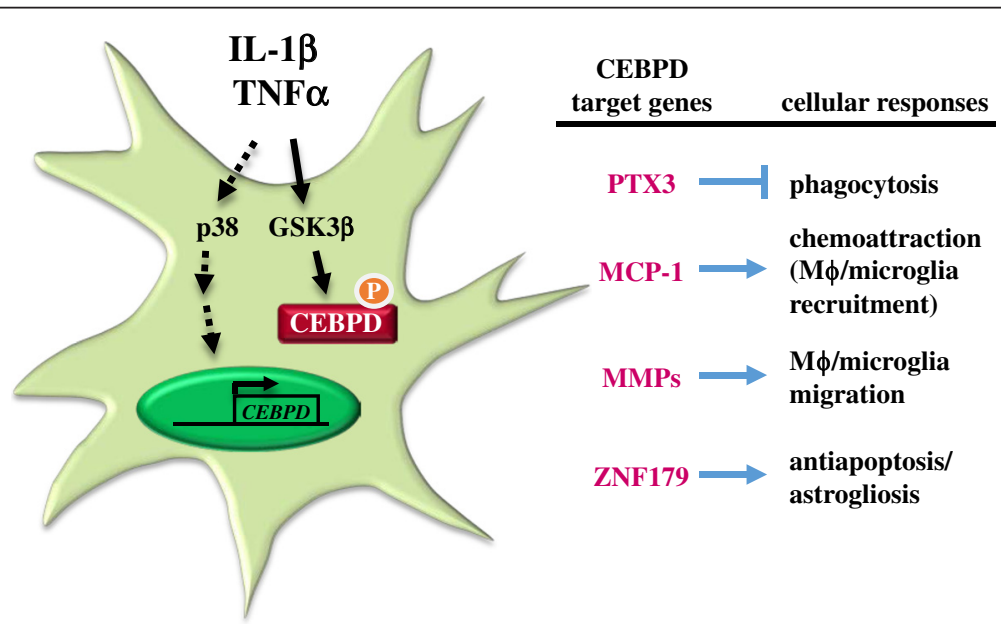

Figure 1 Functional roles of astrocytic CEBPD. 
central nervous system (CNS) and causes demyelination and variable axonal loss. It is characterized by multiple lesions (plaques) involving the brain and spinal cord and has an unpredictable clinical course. Experimental autoimmune encephalomyelitis (EAE) is the most commonly used experimental model for the human inflammatory demyelinating disease, MS. Mice deficient in Cebpd expression exhibited less severe clinical disease than wild-type littermates in response to induction of EAE by vaccination with a myelin oligodendrocyte glycoprotein fragment [82]. This study suggested that CEBPD suppresses expression of IL-10 in dendritic cells (DC), favoring Th17 over Treg development. These findings indicated that CEBPD plays a functional role in both DC and CNS autoimmune inflammatory disease via altering the Th17:Treg balance in an IL-10 dependent fashion.

\section{The role of CEBPD in macrophages of the tumor microenvironment}

Epidemiological studies and animal experiments have suggested that inflammation can increase the risk of normal cells developing into tumorigenic cells as well as enhance cancer cell invasion and metastasis. Moreover, the microenvironment of solid tumors is characterized by a reactive stroma containing an abundance of inflammatory mediators, leukocytes, dysregulated vessels and proteolytic enzymes. However, the communication between cancer cells and the surrounding stromal cells, such as macrophages and fibroblasts, remains largely unclear, especially in an inflammation condition.

Tumor-associated macrophages (TAMs), a type of stromal cell, play a crucial role in promoting the progression of certain cancers. TAMs have an M2 phenotype and function in the promotion of tumor cell proliferation, angiogenesis and constitutive matrix turnover as well as in the repression of adaptive immunity $[83,84]$. The tumor- promoting properties of macrophages have been further revealed due to their ability to synthesize and secrete inhibitory factors that suppress anti-tumor effectors of the host. COX-2 is commonly activated in cancer cells, resulting in the production of PGE2, which exerts strong immunosuppressive effects on cell-mediated immune mechanisms $[85,86]$.

One study demonstrated that Cebpd $d^{-1-} / H E R 2 /$ neu mice exhibit increased mammary tumor multiplicity and decreased lung metastasis [87]. The study agreed with the speculation that CEBPD acts as a tumor suppressor in cancer cells [88]. In addition, the hypoxia environment in cancer can induce CEBPD expression and contributes to the metastasis and invasion of cancer cells [87]. Actually, the decreased lung metastasis may also implied that the existence of CEBPD in stromal cells, such as fibroblasts or macrophages, in tumor microenvironment might contribute to invasion/metastasis. We found that CEBPD regulates or co-regulates a wide range of inflammatory factors, such as TNF $\alpha$, IL-1 $\beta$, IL-6, CXCL1, IL-17A [79], and the chemokines, monocyte chemoattractant protein 1 (MCP1) and IL-10 [30,32,89]. Therefore, several interesting and valuable issues were raised and should be addressed including (I) an investigation of the regulation of CEBPD expression in the cells surrounding a tumor, such as TAMs, and (II) a dissection of the contributions of CEBPD and the consequent effects of its activation within the tumor microenvironment.

As mentioned above, CEBPD directly regulates $\mathrm{COX}-2$ gene expression [46]. We also demonstrated that PGE2 positively regulated CEBPD expression through HuRmediated posttranscriptional regulation in macrophages. Moreover, a cancer cell allograft mouse model provided evidence to support the idea that CEBPD plays a role in cancer growth in the protumor microenvironment [32]. Importantly, in TAMs, the CEBPD downstream target

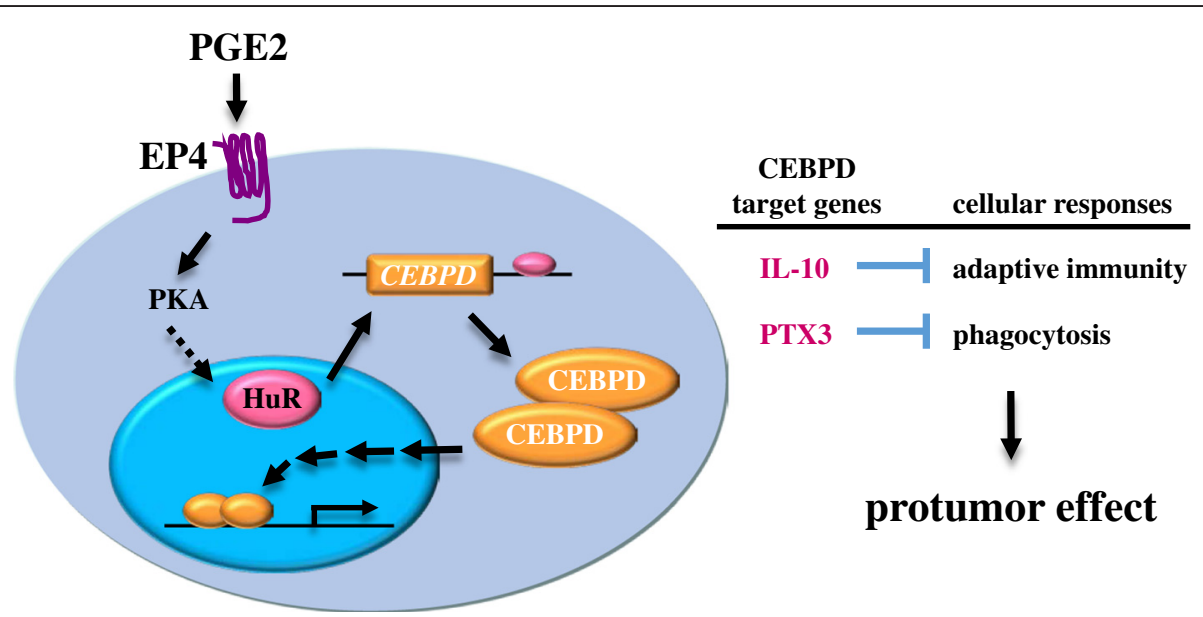

Figure 2 CEBPD in tumor-associated macrophages ( $M 2 M \varphi$ ). 
PTX3 and IL-10 were shown to suppress the ability of macrophages to phagocytose cancer cells and provide immunosuppressive effect, respectively [32]. The functional roles of PGE2-induced CEBPD in macrophages of the tumor microenvironment are shown in Figure 2. This study successfully revealed a new insight of CEBPD in the communication between cancer cells and the tumor microenvironment, especially in macrophages. Moreover, the results of this study also implied that the dissection of CEBPD's roles in the tumor microenvironment could provide a great opportunity to develop a feasible translational application for cancer therapy.

\section{Conclusion}

In this review, we highlighted the role of CEBPD during inflammation and inflammation-related diseases, including cancers. Recent studies have partly revealed the roles of CEBPD in inflammation and have uncovered much about CEBPD biology, especially in various cell types; however, the effects of these roles and their crosstalk between different cell types remain largely unknown. In addition, we know that posttranslational modification of proteins plays an important role in the precise function and correct response of cells to external stimuli; however, how these posttranslational modifications affect the function of CEBPD or how specific proteins interact with CEBPD and affect CEBPD's roles in cell-typespecific manners is still unknown. CEBPD has been linked to many cellular functions and inflammatory diseases. Therefore, new insights into CEBPD's involvement and regulation will be helpful to better understand the complexity and diversity of inflammatory processes and will also identify targets for the development of therapeutic drugs and strategies to overcome inflammation-related diseases involving CEBPD.

\section{Competing interests}

The authors declare that they have no competing interests.

\section{Authors' contributions}

CYK and JMW wrote the manuscript. WCC and JMW edited the manuscript. All authors read and approved the final manuscript.

\footnotetext{
Author details

${ }^{1}$ Program for Neural Regenerative Medicine, College of Medical Science and Technology, Taipei Medical University, Taipei 11031, Taiwan. ${ }^{2}$ Center for Neurotrauma and Neuroregeneration, Taipei Medical University, Taipei 11031, Taiwan. ${ }^{3}$ Graduate Institute of Medical Sciences, College of Medicine, Taipei Medical University, Taipei 11031, Taiwan. ${ }^{4}$ Institute of Bioinformatics and Biosignal Transduction, College of Bioscience and Biotechnology, National Cheng Kung University, Tainan 70101, Taiwan. ${ }^{5}$ Infectious Disease and Signaling Research Center, National Cheng Kung University, Tainan 70101, Taiwan. ${ }^{6}$ Center of Molecular Inflammation, National Cheng Kung University, Tainan 70101, Taiwan.
}

Received: 29 August 2014 Accepted: 25 December 2014

Published online: 16 January 2015

\section{References}

1. Wu Z, Bucher NL, Farmer SR. Induction of peroxisome proliferator-activated receptor gamma during the conversion of $3 \mathrm{~T} 3$ fibroblasts into adipocytes is mediated by C/EBPbeta, C/EBPdelta, and glucocorticoids. Mol Cell Biol. 1996;16(8):4128-36.

2. Tanaka T, Yoshida N, Kishimoto T, Akira S. Defective adipocyte differentiation in mice lacking the C/EBPbeta and/or C/EBPdelta gene. Embo J. 1997;16(24):7432-43.

3. Scott LM, Civin Cl, Rorth P, Friedman AD. A novel temporal expression pattern of three C/EBP family members in differentiating myelomonocytic cells. Blood. 1992;80(7):1725-35.

4. Cardinaux JR, Magistretti PJ. Vasoactive intestinal peptide, pituitary adenylate cyclase-activating peptide, and noradrenaline induce the transcription factors CCAAT/enhancer binding protein (C/EBP)-beta and C/EBP delta in mouse cortical astrocytes: involvement in cAMP-regulated glycogen metabolism. J Neurosci. 1996;16(3):919-29.

5. Zannetti C, Bonnay F, Takeshita F, Parroche P, Menetrier-Caux C, Tommasino M, et al. C/EBP\{delta\} and STAT-1 are required for TLR8 transcriptional activity. J Biol Chem. 2010;285(45):34773-80.

6. Ramji DP, Foka P. CCAAT/enhancer-binding proteins: structure, function and regulation. Biochem J. 2002;365(Pt 3):561-75.

7. Osada S, Yamamoto H, Nishihara T, Imagawa M. DNA binding specificity of the CCAAT/enhancer-binding protein transcription factor family. J Biol Chem. 1996;271(7):3891-6.

8. Cao Z, Umek RM, McKnight SL. Regulated expression of three C/EBP isoforms during adipose conversion of 3 T3-L1 cells. Genes Dev. 1991;5 (9):1538-52.

9. Wang WL, Lee YC, Yang WM, Chang WC, Wang JM. Sumoylation of LAP1 is involved in the HDAC4-mediated repression of COX-2 transcription. Nucleic Acids Res. 2008;36(19):6066-79.

10. Xia C, Cheshire JK, Patel H, Woo P. Cross-talk between transcription factors NF-kappa B and C/EBP in the transcriptional regulation of genes. Int J Biochem Cell Biol. 1997;29(12):1525-39.

11. MacDougald OA, Cornelius P, Lin FT, Chen SS, Lane MD. Glucocorticoids reciprocally regulate expression of the CCAAT/enhancer-binding protein alpha and delta genes in 3 T3-L1 adipocytes and white adipose tissue. J Biol Chem. 1994;269(29):19041-7.

12. Yeh WC, Cao Z, Classon M, McKnight SL. Cascade regulation of terminal adipocyte differentiation by three members of the C/EBP family of leucine zipper proteins. Genes Dev. 1995;9(2):168-81.

13. Yang $\mathrm{H}$, Mammen J, Wei W, Menconi M, Evenson A, Fareed M, et al. Expression and activity of C/EBPbeta and delta are upregulated by dexamethasone in skeletal muscle. J Cell Physiol. 2005;204(1):219-26.

14. MacDougald OA, Cornelius P, Liu R, Lane MD. Insulin regulates transcription of the CCAAT/enhancer binding protein (C/EBP) alpha, beta, and delta genes in fully-differentiated 3 T3-L1 adipocytes. J Biol Chem. 1995;270(2):647-54.

15. Lai $P H$, Wang $W L$, Ko CY, Lee YC, Yang WM, Shen TW, et al. HDAC1/HDAC3 modulates PPARG2 transcription through the sumoylated CEBPD in hepatic lipogenesis. Biochim Biophys Acta. 2008;1783(10):1803-14.

16. Wang JM, Tseng JT, Chang WC. Induction of human NF-IL6beta by epidermal growth factor is mediated through the p38 signaling pathway and cAMP response element-binding protein activation in A431 cells. Mol Biol Cell. 2005;16(7):3365-76.

17. Cantwell CA, Sterneck E, Johnson PF. Interleukin-6-specific activation of the C/EBPdelta gene in hepatocytes is mediated by Stat3 and Sp1. Mol Cell Biol. 1998;18(4):2108-17.

18. Sanford DC, DeWille JW. C/EBPdelta is a downstream mediator of IL-6 induced growth inhibition of prostate cancer cells. Prostate. 2005;63(2):143-54.

19. Alam T, An MR, Papaconstantinou J. Differential expression of three C/EBP isoforms in multiple tissues during the acute phase response. J Biol Chem. 1992;267(8):5021-4.

20. Kinoshita S, Akira S, Kishimoto T. A member of the C/EBP family, NF-IL6 beta, forms a heterodimer and transcriptionally synergizes with NF-IL6. Proc Natl Acad Sci U S A. 1992;89(4):1473-6.

21. Liu YW, Chen CC, Tseng HP, Chang WC. Lipopolysaccharide-induced transcriptional activation of interleukin-10 is mediated by MAPK-and NF-kappaB-induced CCAAT/enhancer-binding protein delta in mouse macrophages. Cell Signal. 2006;18(9):1492-500.

22. Balamurugan K, Sharan S, Klarmann KD, Zhang Y, Coppola V, Summers GH, et al. FBXW7alpha attenuates inflammatory signalling by downregulating C/EBPdelta and its target gene Trr4. Nat Commun. 2013;4:1662. 
23. Kravchenko W, Mathison JC, Schwamborn K, Mercurio F, Ulevitch RJ. IKKi/ IKKepsilon plays a key role in integrating signals induced by proinflammatory stimuli. J Biol Chem. 2003;278(29):26612-9.

24. Maitra U, Gan L, Chang S, Li L. Low-dose endotoxin induces inflammation by selectively removing nuclear receptors and activating CCAAT/enhancerbinding protein delta. J Immunol. 2011;186(7):4467-73.

25. Banerjee S, Xie N, Cui H, Tan Z, Yang S, Icyuz M, et al. MicroRNA let-7c regulates macrophage polarization. J Immunol. 2013;190(12):6542-9.

26. Tengku-Muhammad TS, Hughes TR, Ranki H, Cryer A, Ramji DP. Differential regulation of macrophage CCAAT-enhancer binding protein isoforms by lipopolysaccharide and cytokines. Cytokine. 2000;12(9):1430-6.

27. Yin M, Yang SQ, Lin HZ, Lane MD, Chatterjee S, Diehl AM. Tumor necrosis factor alpha promotes nuclear localization of cytokine-inducible CCAAT/ enhancer binding protein isoforms in hepatocytes. J Biol Chem. 1996;271 (30):17974-8.

28. Cardinaux JR, Allaman I, Magistretti PJ. Pro-inflammatory cytokines induce the transcription factors C/EBPbeta and C/EBPdelta in astrocytes. Glia. 2000;29(1):91-7

29. Ko CY, Chang LH, Lee YC, Sterneck E, Cheng CP, Chen SH, et al. CCAAT/ enhancer binding protein delta (CEBPD) elevating PTX3 expression inhibits macrophage-mediated phagocytosis of dying neuron cells. Neurobiol Aging. 2012;33(2):422 e411-425

30. Ko CY, Wang WL, Wang SM, Chu YY, Chang WC, Wang JM. Glycogen synthase kinase-3beta-mediated CCAAT/enhancer-binding protein delta phosphorylation in astrocytes promotes migration and activation of microglia/macrophages. Neurobiol Aging. 2014;35(1):24-34.

31. Ji C, Chang W, Centrella M, McCarthy TL. Activation domains of CCAAT enhancer binding protein delta: regions required for native activity and prostaglandin E2-dependent transactivation of insulin-like growth factor I gene expression in rat osteoblasts. Mol Endocrinol. 2003;17(9):1834-43.

32. Hsiao YW, Li CF, Chi JY, Tseng JT, Chang Y, Hsu LJ, et al. CCAAT/enhancer binding protein delta in macrophages contributes to immunosuppression and inhibits phagocytosis in nasopharyngeal carcinoma. Sci Signal. 2013;6 (284):ra59.

33. McCarthy TL, Yun Z, Madri JA, Centrella M. Stratified control of IGF-I expression by hypoxia and stress hormones in osteoblasts. Gene. 2014;539(1):141-51.

34. Juan TS, Wilson DR, Wilde MD, Darlington GJ. Participation of the transcription factor C/EBP delta in the acute-phase regulation of the human gene for complement component C3. Proc Natl Acad Sci U S A. 1993;90 (7):2584-8.

35. Poli $\mathrm{V}$. The role of $\mathrm{C} / \mathrm{EBP}$ isoforms in the control of inflammatory and native immunity functions. J Biol Chem. 1998;273(45):29279-82.

36. Moore F, Santin I, Nogueira TC, Gurzov EN, Marselli L, Marchetti P, et al. The transcription factor C/EBP delta has anti-apoptotic and anti-inflammatory roles in pancreatic beta cells. PLoS One. 2012;7(2):e31062.

37. Sekine O, Nishio Y, Egawa K, Nakamura T, Maegawa H, Kashiwagi A. Insulin activates CCAAT/enhancer binding proteins and proinflammatory gene expression through the phosphatidylinositol 3-kinase pathway in vascular smooth muscle cells. J Biol Chem. 2002;277(39):36631-9.

38. Sarkar TR, Sharan S, Wang J, Pawar SA, Cantwell CA, Johnson PF, et al. Identification of a Src tyrosine kinase/SIAH2 E3 ubiquitin ligase pathway that regulates C/EBPdelta expression and contributes to transformation of breast tumor cells. Mol Cell Biol. 2012;32(2):320-32.

39. Cao Y, Prescott SM. Many actions of cyclooxygenase-2 in cellular dynamics and in cancer. J Cell Physiol. 2002;190(3):279-86.

40. Thomas B, Berenbaum F, Humbert L, Bian H, Bereziat G, Crofford L, et al. Critical role of C/EBPdelta and C/EBPbeta factors in the stimulation of the cyclooxygenase-2 gene transcription by interleukin-1beta in articular chondrocytes. Eur J Biochem. 2000;267(23):6798-809.

41. Wadleigh DJ, Reddy ST, Kopp E, Ghosh S, Herschman HR. Transcriptional activation of the cyclooxygenase-2 gene in endotoxin-treated RAW 264.7 macrophages. J Biol Chem. 2000;275(9):6259-66.

42. Chen JJ, Huang WC, Chen CC. Transcriptional regulation of cyclooxygenase-2 in response to proteasome inhibitors involves reactive oxygen speciesmediated signaling pathway and recruitment of CCAAT/enhancer-binding protein delta and CREB-binding protein. Mol Biol Cell. 2005;16(12):5579-91.

43. Ashwell JD. The many paths to p38 mitogen-activated protein kinase activation in the immune system. Nat Rev Immunol. 2006;6(7):532-40.

44. Geng Y, Valbracht J, Lotz M. Selective activation of the mitogen-activated protein kinase subgroups c-Jun NH2 terminal kinase and p38 by IL-1 and TNF in human articular chondrocytes. J Clin Invest. 1996;98(10):2425-30.
45. Symons A, Beinke S, Ley SC. MAP kinase kinase kinases and innate immunity. Trends Immunol. 2006;27(1):40-8.

46. Wang JM, Ko CY, Chen LC, Wang WL, Chang WC. Functional role of NF-IL6beta and its sumoylation and acetylation modifications in promoter activation of cyclooxygenase 2 gene. Nucleic Acids Res. 2006;34(1):217-31.

47. Pan YC, Li CF, Ko CY, Pan MH, Chen PJ, Tseng JT, et al. CEBPD reverses RB/ E2F1-mediated gene repression and participates in HMDB-induced apoptosis of cancer cells. Clin Cancer Res. 2010;16(23):5770-80.

48. Liu YW, Wang SA, Hsu TY, Chen TA, Chang WC, Hung JJ. Inhibition of LPS-induced C/EBP delta by trichostatin A has a positive effect on LPS-induced cyclooxygenase 2 expression in RAW264.7 cells. J Cell Biochem. 2010;110(6):1430-8.

49. Ruminy P, Gangneux C, Claeyssens S, Scotte M, Daveau M, Salier JP. Gene transcription in hepatocytes during the acute phase of a systemic inflammation: from transcription factors to target genes. Inflamm Res. 2001;50(8):383-90.

50. Gilpin DA, Hsieh CC, Kuninger DT, Herndon DN, Papaconstantinou J. Effect of thermal injury on the expression of transcription factors that regulate acute phase response genes: the response of C/EBP alpha, C/EBP beta, and C/EBP delta to thermal injury. Surgery. 1996;119(6):674-83.

51. Koj A. Initiation of acute phase response and synthesis of cytokines. Biochim Biophys Acta. 1996;1317(2):84-94.

52. Ray A, Ray BK. Serum amyloid A gene expression under acute-phase conditions involves participation of inducible C/EBP-beta and C/EBP-delta and their activation by phosphorylation. Mol Cell Biol. 1994;14(6):4324-32.

53. Litvak V, Ramsey SA, Rust AG, Zak DE, Kennedy KA, Lampano AE, et al. Function of C/EBPdelta in a regulatory circuit that discriminates between transient and persistent TLR4-induced signals. Nat Immunol. 2009;10(4):437-43.

54. Yan C, Johnson PF, Tang H, Ye Y, Wu M, Gao H. CCAAT/enhancer-binding protein delta is a critical mediator of lipopolysaccharide-induced acute lung injury. Am J Pathol. 2013;182(2):420-30.

55. Do-Umehara HC, Chen C, Urich D, Zhou L, Qiu J, Jang S, et al. Suppression of inflammation and acute lung injury by Miz1 via repression of C/EBP-delta. Nat Immunol. 2013;14(5):461-9.

56. Yan C, Ward PA, Wang X, Gao H. Myeloid depletion of SOCS3 enhances LPS-induced acute lung injury through CCAAT/enhancer binding protein delta pathway. FASEB J. 2013;27(8):2967-76.

57. Duitman J, Hoogendijk AJ, Groot AP, de Sousa RR R, van der Poll T, Florquin $\mathrm{S}$, et al. CCAAT-enhancer binding protein delta (C/EBPdelta) protects against Klebsiella pneumoniae-induced pulmonary infection: potential role for macrophage migration. J Infect Dis. 2012;206(12):1826-35.

58. Duitman J, Schouten M, Groot AP, Borensztajn KS, Daalhuisen JB, Florquin S, et al. CCAAT/enhancer-binding protein delta facilitates bacterial dissemination during pneumococcal pneumonia in a platelet-activating factor receptordependent manner. Proc Natl Acad Sci U S A. 2012;109(23):9113-8.

59. Lu YC, Kim I, Lye E, Shen F, Suzuki N, Suzuki S, et al. Differential role for c-Rel and C/EBPbeta/delta in TLR-mediated induction of proinflammatory cytokines. J Immunol. 2009;182(11):7212-21.

60. Tsukada J, Yoshida Y, Kominato Y, Auron PE. The CCAAT/enhancer (C/EBP) family of basic-leucine zipper (bZIP) transcription factors is a multifaceted highly-regulated system for gene regulation. Cytokine. 2011;54(1):6-19.

61. Yan C, Zhu M, Staiger J, Johnson PF, Gao H. C5a-regulated CCAAT/enhancerbinding proteins beta and delta are essential in Fcgamma receptor-mediated inflammatory cytokine and chemokine production in macrophages. J Biol Chem. 2012;287(5):3217-30.

62. Slofstra SH, Groot AP, Obdeijn MH, Reitsma PH, ten Cate H, Spek CA. Gene expression profiling identifies C/EBPdelta as a candidate regulator of endotoxin-induced disseminated intravascular coagulation. Am J Respir Crit Care Med. 2007;176(6):602-9.

63. Takata Y, Kitami Y, Yang ZH, Nakamura M, Okura T, Hiwada K. Vascular inflammation is negatively autoregulated by interaction between CCAAT/ enhancer-binding protein-delta and peroxisome proliferator-activated receptor-gamma. Circ Res. 2002;91(5):427-33.

64. Gao H, Bryzgalova G, Hedman E, Khan A, Efendic S, Gustafsson JA, et al. Long-term administration of estradiol decreases expression of hepatic lipogenic genes and improves insulin sensitivity in ob/ob mice: a possible mechanism is through direct regulation of signal transducer and activator of transcription 3. Mol Endocrinol. 2006;20(6):1287-99.

65. Nishioka K, Ohshima S, Umeshita-Sasai M, Yamaguchi N, Mima T, Nomura S, et al. Enhanced expression and DNA binding activity of two CCAAT/enhancerbinding protein isoforms, C/EBPbeta and C/EBPdelta, in rheumatoid synovium. Arthritis Rheum. 2000;43(7):1591-6. 
66. Li R, Strohmeyer R, Liang Z, Lue LF, Rogers J. CCAAT/enhancer binding protein delta (C/EBPdelta) expression and elevation in Alzheimer's disease. Neurobiol Aging. 2004;25(8):991-9.

67. Glass CK, Saijo K, Winner B, Marchetto MC, Gage FH. Mechanisms underlying inflammation in neurodegeneration. Cell. 2010;140(6):918-34.

68. Perez-Capote K, Saura J, Serratosa J, Sola C. Expression of C/EBPalpha and C/EBPbeta in glial cells in vitro after inducing glial activation by different stimuli. Neurosci Lett. 2006;410(1):25-30

69. Wang SM, Lee YC, Ko CY, Lai MD, Lin DY, Pao PC, et al. Increase of Zinc Finger Protein 179 in Response to CCAAT/Enhancer Binding Protein Delta Conferring an Antiapoptotic Effect in Astrocytes of Alzheimer's Disease. Mol Neurobiol 2014. 01 May.

70. Loane DJ, Pocivavsek A, Moussa CE, Thompson R, Matsuoka Y, Faden Al, et al. Amyloid precursor protein secretases as therapeutic targets for traumatic brain injury. Nat Med. 2009;15(4):377-9.

71. Van Den Heuvel C, Thornton E, Vink R. Traumatic brain injury and Alzheimer's disease: a review. Prog Brain Res. 2007;161:303-16.

72. Breunig JJ, Guillot-Sestier MV, Town T. Brain injury, neuroinflammation and Alzheimer's disease. Front Aging Neurosci. 2013;5:26.

73. von Gertten C, Flores Morales A, Holmin S, Mathiesen T, Nordqvist AC. Genomic responses in rat cerebral cortex after traumatic brain injury. BMC Neurosci. 2005;6:69.

74. Nathan C, Calingasan N, Nezezon J, Ding A, Lucia MS, La Perle K, et al. Protection from Alzheimer's-like disease in the mouse by genetic ablation of inducible nitric oxide synthase. J Exp Med. 2005;202(9):1163-9.

75. Won JS, Im YB, Key L, Singh I, Singh AK. The involvement of glucose metabolism in the regulation of inducible nitric oxide synthase gene expression in glial cells: possible role of glucose-6-phosphate dehydrogenase and CCAAT/enhancing binding protein. J Neurosci. 2003;23(20):7470-8.

76. Valente T, Straccia M, Gresa-Arribas N, Dentesano G, Tusell JM, Serratosa J, et al. CCAAT/enhancer binding protein delta regulates glial proinflammatory gene expression. Neurobiol Aging. 2013;34(9):2110-24.

77. Kinne RW, Stuhlmuller B, Burmester GR. Cells of the synovium in rheumatoid arthritis. Macrophages. Arthritis Res Ther. 2007:9(6):224.

78. Feldmann M. Development of anti-TNF therapy for rheumatoid arthritis. Nat Rev Immunol. 2002;2(5):364-71.

79. Chang LH, Huang HS, Wu PT, Jou IM, Pan MH, Chang WC, et al. Role of macrophage CCAAT/enhancer binding protein delta in the pathogenesis of rheumatoid arthritis in collagen-induced arthritic mice. PLoS One. 2012;7(9):e45378.

80. Kuo YC, Lai CS, Wang JM, Badmaev V, Nagabhushanam K, Ho CT, et al. Differential inhibitory effects of inotilone on inflammatory mediators, inducible nitric oxide synthase and cyclooxygenase-2, in LPS-stimulated murine macrophage. Mol Nutr Food Res. 2009;53(11):1386-95.

81. Lai CS, Lee JH, Ho CT, Liu CB, Wang JM, Wang YJ, et al. Rosmanol potently inhibits lipopolysaccharide-induced iNOS and COX-2 expression through downregulating MAPK, NF-kappaB, STAT3 and C/EBP signaling pathways. J Agric Food Chem. 2009;57(22):10990-8.

82. Tsai WW, Mohammad MG, Tolhurst O, Breit SN, Sawchenko PE, Brown DA CCAAT/enhancer binding protein-delta expression by dendritic cells regulates CNS autoimmune inflammatory disease. J Neurosci. 2011;31(48):17612-21.

83. Pollard JW. Tumour-educated macrophages promote tumour progression and metastasis. Nat Rev Cancer. 2004;4(1):71-8.

84. Solinas G, Germano G, Mantovani A, Allavena P. Tumor-associated macrophages (TAM) as major players of the cancer-related inflammation. J Leukoc Biol. 2009;86(5):1065-73.

85. Wojtowicz-Praga S. Reversal of tumor-induced immunosuppression: a new approach to cancer therapy. J Immunother. 1997;20(3):165-77.

86. Lee CH, Yeh TH, Lai HC, Wu SY, Su IJ, Takada K, et al. Epstein-Barr virus Zta-induced immunomodulators from nasopharyngeal carcinoma cells upregulate interleukin-10 production from monocytes. J Virol. 2011;85 (14):7333-42.

87. Balamurugan K, Wang JM, Tsai HH, Sharan S, Anver M, Leighty R, et al. The tumour suppressor C/EBPdelta inhibits FBXW7 expression and promotes mammary tumour metastasis. EMBO J. 2010;29(24):4106-17.
88. Balamurugan K, Sterneck E. The many faces of C/EBPdelta and their relevance for inflammation and cancer. Int J Biol Sci. 2013:9(9):917-33.

89. Sato $Y$, Nishio $Y$, Sekine $O$, Kodama K, Nagai Y, Nakamura T, et al. Increased expression of CCAAT/enhancer binding protein-beta and -delta and monocyte chemoattractant protein-1 genes in aortas from hyperinsulinaemic rats. Diabetologia. 2007;50(2):481-9.

\section{Submit your next manuscript to BioMed Central and take full advantage of:}

- Convenient online submission

- Thorough peer review

- No space constraints or color figure charges

- Immediate publication on acceptance

- Inclusion in PubMed, CAS, Scopus and Google Scholar

- Research which is freely available for redistribution 